\title{
Fundamental study on the mechanism of DNA degradation in tissues fixed in formaldehyde
}

\author{
Y Tokuda, T Nakamura, K Satonaka, S Maeda, K Doi, S Baba, T Sugiyama
}

\begin{abstract}
The mechanism of DNA degradation and its clinical applications were examined. When purified $\lambda$ phage and extracted liver DNA were fixed in phosphate buffered formaldehyde, the DNA did not degrade, but there was incomplete digestion with endonuclease. Rat liver tissues were fixed under various conditions and DNA extracted. Immediate fixation with buffered formaldehyde at low temperature, or the addition of EDTA to buffered formaldehyde blocked the DNA degradation. Analysis of pulsed field gel electrophoresis also showed that DNA was degraded before extraction. These results suggest that tissue nuclease has an important role in DNA degradation in tissue. Furthermore, formaldehyde fixation at low temperature, which may take time and which decreases slightly the staining capacity, is useful for the extraction of intact DNA. For clinical application, the detection of provirus was examined. Genomic DNA was extracted from a necropsy sample of adult $T$ cell leukaemia fixed in formaldehyde; human $T$ cell leukaemia virus type-I (HTLV-I) provirus was successfully detected by Southern blotting.
\end{abstract}

Molecular biology has developed rapidly over the past few years and the genetic abnormalities of many diseases have been elucidated as a result. DNA for gene analysis, however, has, to date, been obtained from fresh frozen tissues, making it impossible for retrospective studies to be carried out. Recently the use of ancient $\mathrm{DNA}^{1}$ and paraffin wax embedded pathology specimens has been reported as another source..$^{2-4}$ Other trials using cells and tissues fixed in Carnoy's solution and ethanol, ${ }^{5}$ or stored bone marrow slides, have also been reported. ${ }^{6}$ Pathology tissues have usually been fixed in formaldehyde, however, and in 1985 Goelz first reported that high molecular DNA could be extracted from tissues fixed in formaldehyde and embedded in paraffin wax. ${ }^{2}$ The polymerase chain reaction (PCR) facilitated the detection of specific genes from paraffin wax embedded tissues which contained relatively low molecular DNA. ${ }^{5}$ We also extracted DNA from formaldehyde fixed tissues, but the extracted DNA was degraded. We therefore examined the mechanism of DNA degradation. Furthermore, genomic DNA was extracted from a necropsy specimen fixed in formaldehyde and used for the detection of HTLV-I provirus.

\section{Methods}

To ascertain the direct effect of formaldehyde on DNA $100 \mu \mathrm{g}$ of $\lambda$ phage DNA (Takara, Kyoto, Japan), salmon sperm DNA, and extracted rat liver DNA were fixed in phosphate buffered formaldehyde (formaldehyde concentration $4.3 \%$, methanol concentration $0.7 \%, 33 \mathrm{mM} \mathrm{NaH} \mathrm{PO}_{4}, 45 \cdot 7 \mathrm{mM} \mathrm{Na} \mathrm{HPO}_{4}$, $\mathrm{pH} \mathrm{7)} \mathrm{for} 24$ hours at room temperature and dialysed once in TNE (10 mM TRIS- $\mathrm{HCl}$, $\mathrm{pH} 8,1 \mathrm{mM}$ EDTA, $100 \mathrm{mM} \mathrm{NaCl}$ ) to remove the formaldehyde.

Closed colony Long-Evans (LE) rats were used to study the effect under different fixation conditions. After anaesthesia with ether and laparotomy buffered formaldehyde was immediately injected into the portal vein. After resection the liver was minced with a razor blade, washed with buffered formaldehyde, and fixed under various conditions. Buffered formaldehyde was checked for $\mathrm{pH}$ every day and changed to prevent acidosis. Part of the tissue specimens were embedded in paraffin wax blocks and cut into thin slices using the microtome. These were stained with haematoxylin and eosin.

Further tissue was obtained three hours after the death of a patient with adult $T$ cell leukaemia. Half the tissue was frozen and the other half fixed in phosphate buffered formaldehyde at room temperature for two days.

These fresh and fixed samples were frozen in an ethanol dry-ice bath and maintained at $-80^{\circ} \mathrm{C}$ until DNA was extracted.

DNA EXTRACTION AND DETECTION IN SAMPLES After fixation in formaldehyde, tissues were washed with water and homogenised with polytron (Kinematika, Luzern, Switzerland) in TRIS-EDTA solution (50 mM TRIS$\mathrm{HCl}, \mathrm{pH}$ 7·6, $20 \mathrm{mM}$ EDTA, $100 \mathrm{mM} \mathrm{NaCl}$ ). High molecular weight DNA was extracted from fresh samples by the method of GrossBellard, ${ }^{7}$ and DNA was extracted from formaldehyde fixed tissues by the method of Goelz. ${ }^{2}$ The extracted DNA was precipitated with ethanol and dissolved in $1 \times$ TE $(10 \mathrm{mM}$ TRIS-HCl, pH 7·6, 1 mM EDTA).

PULSED FIELD GEL ELECTROPHORESIS (PFG)

The K3D cell line (a 7,12-dimethylben(a) anthracene (DMBA) induced erythroleukaemia cell line established from Long-Evans rats $^{8}$ ) was used for PFG analysis. About $1 \times$ $10^{7}$ cells of $\mathrm{K} 3 \mathrm{D}$ were centrifuged. The sediment was resuspended in phosphate buffered formaldehyde and fixed at room temperature. The suspension was dialysed in $1 \times$ TNE to remove formaldehyde. The cells were centrifuged again, prepared in agarose plugs, 


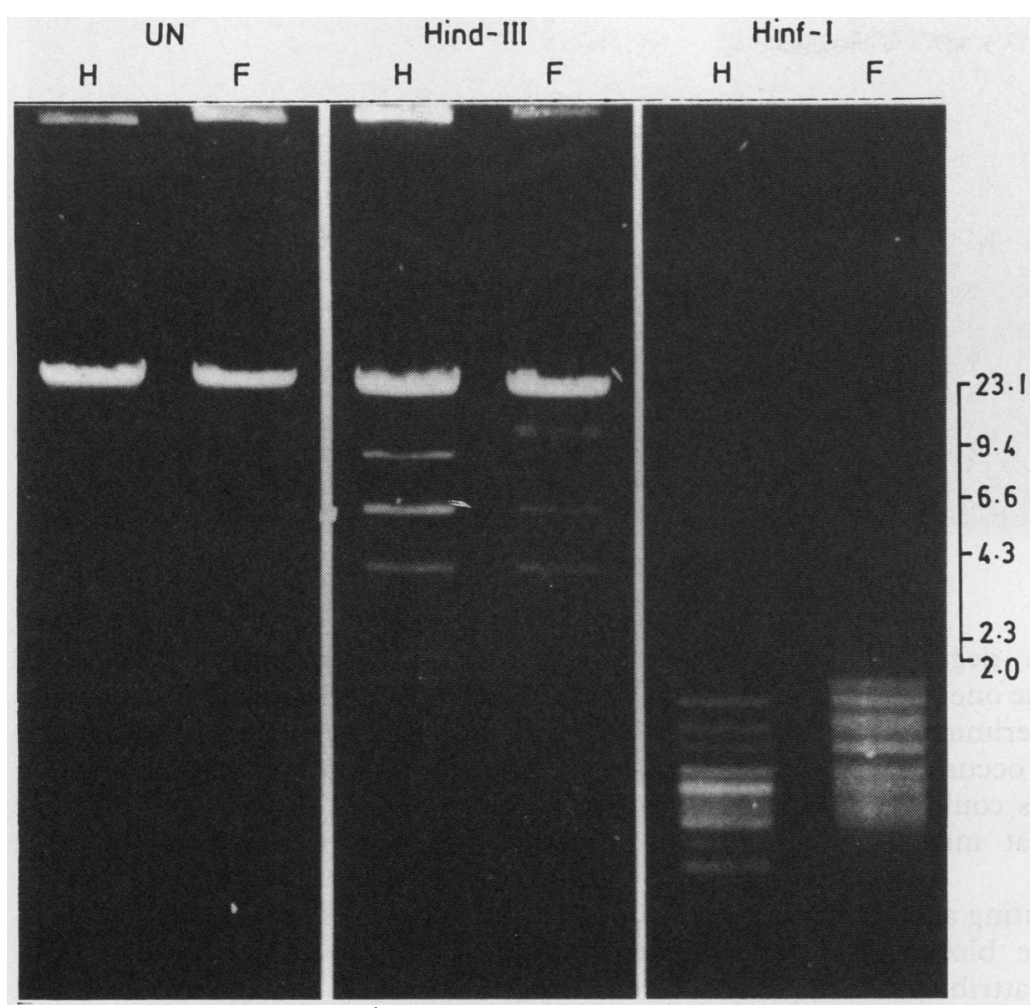

Figure 1 Direct formaldehyde effect on extracted $\lambda$ phage DNA: $\lambda$ phage DNA was fixed in phosphate buffered formaldehyde at room temperature for 24 hours $(F)$, and dissolved in distilled water under the same condition $(H)$. DNA was prepared as described and digested with restriction endonuclease. DNA, undigested (UN) or digested with either Hind-III (Hind-III) or Hinf-I (Hinf-I), was electrophoresed in $0.7 \%$ agarose gels and stained with ethidium bromide. Band sizes are indicated in kilobase pairs. patient with adult $\mathrm{T}$ cell leukaemia, ${ }^{11}$ was used as a positive control for HTLV-I provirus detection. The DNA was transferred to Biodyne-A nylon membranes (Pall, New York, USA) using the method of Southern. ${ }^{12}$ The HTLV-I probe (clone ${ }_{p}$ MT2) was kindly supplied by Dr M Hatanaka, Virus Research Institute, Kyoto University. ${ }^{13}$ The probe was labelled with $\left[{ }^{32} \mathrm{P}\right] \mathrm{dCTP}$ to a specific activity of $>10^{8} \mathrm{cpm} / \mu \mathrm{g}$ using a nick translation kit (Amersham, Buckinghamshire, England). Filters were prehybridised, hybridised with this probe under previously reported conditions, ${ }^{14}$ and exposed to $\mathrm{RX} x$ ray film (Fuji Photo, Kanagawa, Japan) with a Conta intensifying screen (Dupont, Boston, USA) at $-80^{\circ} \mathrm{C}$ for 24-72 hours.

\section{Results}

DIRECT FORMALDEHYDE EFFECT ON DNA

Lambda phage DNA fixed in phosphate buffered formaldehyde ( $\mathrm{pH} 7$ ) showed the same kilobase pair band as control DNA (fig 1); salmon sperm and extracted rat liver DNA did not degrade either. Genomic DNA, however, degraded in unbuffered formaldehyde to the same degree as that reported by Goelz (data not shown). ${ }^{2}$ Formaldehyde fixation might not have a degrading effect on DNA extracted intact but the extracted $\lambda$ phage DNA treated with endonuclease after formaldehyde fixation showed a different pattern (fig 1).

and placed in $0.9 \%$ agarose gel, as previously described. ${ }^{9}$ For PFG, Gene Line System (Beckman, Birlingame, California, USA) was used and run for 24 hours with a 40 second pulse time, starting at $200-\mathrm{V} .^{10}$

\section{SOUTHERN BLOT ANALYSIS}

DNA extracted from the necropsy samples was used for Southern blotting. After restriction endonuclease digestion (Takara, Kyoto, Japan) the digested DNA was electrophoresed in $0.7^{\circ}$ o agarose gels in $1 \times \operatorname{TAE}(40 \mathrm{mM}$ TRIS-acetate, $\mathrm{pH} 7 \cdot 4,1 \mathrm{mM}$ EDTA). Genomic DNA, extracted from fresh KH-2 cultured cells established from a 49 year old
EFFECT ON DNA DEGRADATION UNDER DIFFERENT FIXATION CONDITIONS

The proportion of intact DNA decreased quickly when tissues were fixed in buffered formaldehyde at room temperature (fig 2A). With immediate fixation, as in the case of the flowing back of the buffered formaldehyde to the portal vein, this degradation speed decreased, but could not be blocked. When the tissues were fixed in buffered formaldehyde at $4^{\circ} \mathrm{C}$, the extracted DNA showed no degradation (fig 2B). When the liver was transferred to formaldehyde kept at room
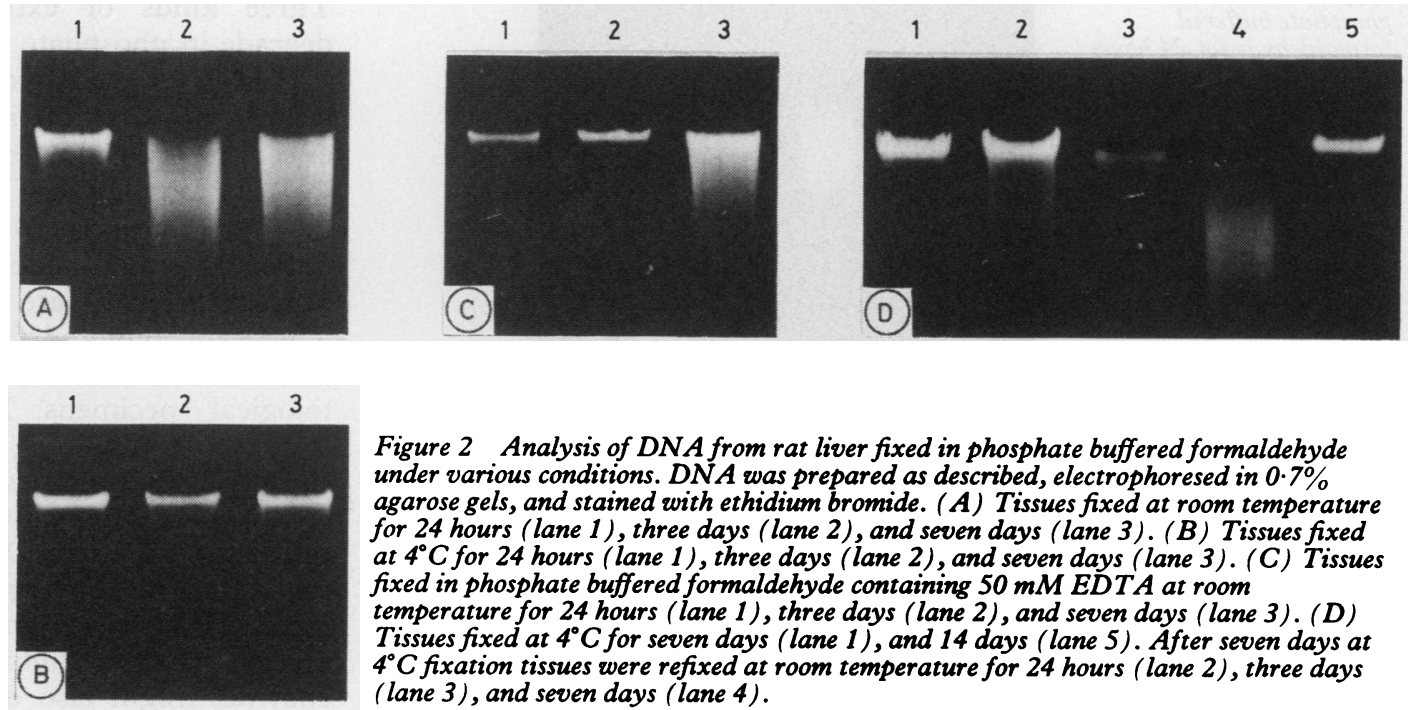

Figure 2 Analysis of DNA from rat liver fixed in phosphate buffered formaldehyde under various conditions. DNA was prepared as described, electrophoresed in $0.7 \%$ agarose gels, and stained with ethidium bromide. (A) Tissues fixed at room temperature for 24 hours (lane 1), three days (lane 2), and seven days (lane 3). (B) Tissues fixed at $4^{\circ} \mathrm{C}$ for 24 hours (lane 1), three days (lane 2), and seven days (lane 3). (C) Tissues fixed in phosphate buffered formaldehyde containing $50 \mathrm{mM} \mathrm{EDTA}$ at room temperature for 24 hours (lane 1), three days (lane 2), and seven days (lane 3). (D) Tissues fixed at $4^{\circ} \mathrm{C}$ for seven days (lane 1 ), and 14 days (lane 5). After seven days a $4^{\circ} \mathrm{C}$ fixation tissues were refixed at room temperature for 24 hours (lane 2 ), three days (lane 3), and seven days (lane 4). 
Figure 3 Microscopic findings of rat liver fixed in phosphate buffered formaldehyde. Tissues were fixed for three days at room temperature $(A)$ and at $4^{\circ} \mathrm{C}(B)$ (haematoxylin and eosin).
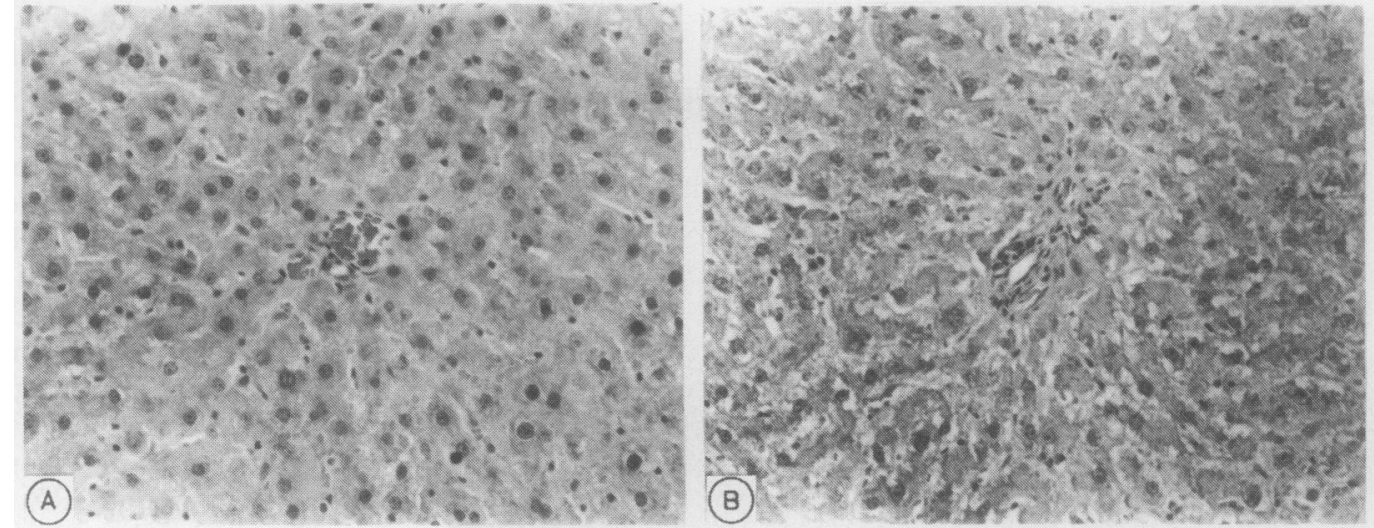

temperature, the DNA degradation might have started even after the one week fixation at $4^{\circ} \mathrm{C}$ (fig 2D). These experiments suggest that DNA degradation could occur during formaldehyde fixation, and this could be attributed to enzymatic action that might have been inhibited at $4^{\circ} \mathrm{C}$ fixation.

EDTA is a metal chelating agent and one of the well known DNAse blockers. If DNA degradation were to be attributed to DNAse during formaldehyde fixation, EDTA should have blocked it. DNA extracted from rat liver which was fixed in formaldehyde containing EDTA degraded, too, but the high molecular elements remained (fig 2C). The DNA degradation was incompletely blocked, so probably some other enzymatic action degraded the intact DNA.

MICROSCOPICAL FINDINGS UNDER DIFFERENT FIXATION CONDITIONS

Fixation with phosphate buffered formaldehyde for 24 hours between room temperature and $4^{\circ} \mathrm{C}$ clearly showed different staining pat-

Figure 4 Analysis of high molecular weight $D N A$ from fixed $K 3 D$ cells. Cells were prepared as described. After PFG $D N A$ was stained with ethidium bromide. Nontreated K3D cells (lane 2), fixed K3D cells in phosphate buffered formaldehyde for 24 hours (lanes 3 and 4), fixed $K 3 D$ cells in phosphate buffered formaldehyde for three days (lanes 5 and 6 ) Molecular weight markers, given in kilobase pairs, were chromosomal $D N A$ of Saccharomyces cerevisiae (lane 1).

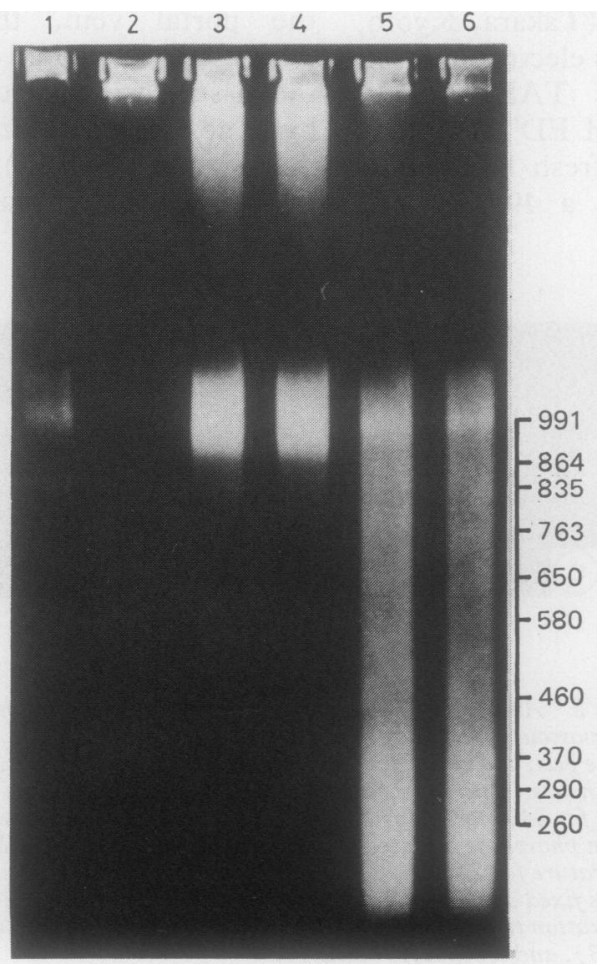

terns. After three days, however, tissue fixed at $4^{\circ} \mathrm{C}$ showed no clear difference from tissues fixed at room temperature, except that the nuclear and cytoplasmic morphology was a little less well preserved (fig $3 \mathrm{~A}$ and B). After five days no differences were discernible (data not shown).

\section{DNA DEGRADATION ANALYSIS BY PFG}

To clarify if mechanical damage had occurred as a result of standard DNA extraction, PFG was used to detect the degree of DNA degradation. PFG, which can separate DNA only by electrical action, was used for visualising very high molecular DNA. DNA degradation was also shown by PFG, and its degree was almost the same as that in standard DNA extraction procedures (fig 4).

HTLV-I PROVIRUS DETECTION FROM FORMALDEHYDE FIXED TISSUES

DNA extracted from formaldehyde fixed samples showed a kilobase pair band pattern similar to that in DNA extracted from fresh samples by Southern blot analysis (fig 5). The signals obtained from the former, however, were weaker than those from the latter. In the KH-2 cultured cell line HTLV-I genes integrated at many sites and amplified during a two year continuous culture.

\section{Discussion}

Three kinds of extracted DNA did not degrade in phosphate buffered formaldehyde. Although formaldehyde was used to analyse histone organisation in the nucleosome, the effect of formaldehyde is known to be reversible. As reported by Goelz, ${ }^{2}$ our study shows that high molecular weight DNA degrades in unbuffered formaldehyde, but does not degrade in phosphate buffered formaldehyde. Therefore, buffered formaldehyde fixation is indicated for DNA preservation in histological specimens. If the $\mathrm{pH}$ of buffered formaldehyde is kept in a neutral condition, the purified DNA does not degrade.

The results of various formaldehyde fixations suggest that DNAse might have an important role in degrading genomic DNA during fixation, and the addition of EDTA to the fixation medium suggests that other enzymes might also degrade genomic DNA. 


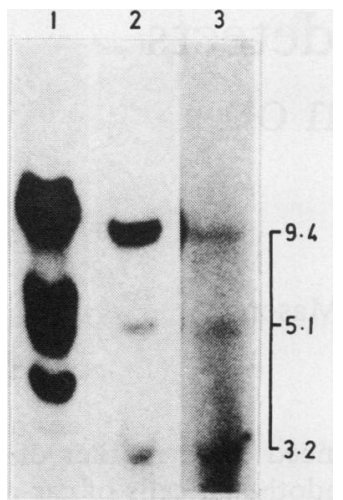

Figure 5 Southern blot analysis of fresh and fixed DNA after digestion with restriction endonuclease. $D N A$ was prepared as described from fresh $\mathrm{KH}-2$ cells (lane 1), fresh liver

(lane 2), and fixed liver (lane 3). DNA was digested with EcoR-I, electrophoresed, transferred to nylon membranes, hybridised with a probe for HTLV $-I$, and autoradiographed for 24 hours (lanes 1 and 2) or 72 hours (lane 3) at $-80^{\circ} \mathrm{C}$. Band sizes are indicated in kilobase pairs.
The PFG study showed that genomic DNA was not destroyed using standard DNA extraction methods, but degraded during formaldehyde fixation. Therefore, blocking of the nuclease action is important for DNA preservation in formaldehyde fixed tissues, and it is recommended that the following be observed: (1) Tissues should be finely minced and well rinsed with formaldehyde immediately after resection. (2) Tissues should be fixed in buffered formaldehyde. (3) Tissues should be fixed at low temperature or in formaldehyde containing nuclease blockers such as EDTA. When tissues are fixed at low temperatures, haematoxylin and eosin staining is negligibly affected. We recommend fixing routine material at low temperatures, because they can then be used for genetic diagnosis.

For the detection of HTLV-I, Southern blot analysis was successfully carried out using DNA extracted from formaldehyde fixed necropsy samples, but the signal strength was considerably reduced in fixed material. Consequently it would be difficult to interpret gene copy numbers under these circumstances. Recent studies have shown that degraded DNA could be used for PCR. ${ }^{4-6}$ Therefore Southern blot analysis for HTLV-I detection has been superseded by the use of PCR-based methods which can work satisfactorily on DNA of much lower quality. The retrospective study, which was first proposed in 1977, may then become possible, but DNA degraded to a high degree is not suitable for PCR. Thus samples should be fixed taking the aforementioned precautions. In this way path- ology specimens can be used for the analysis of oncogene mutation and deletion, provirus integration, and other genetic abnormalities.

1 Paabo S. Molecular cloning of ancient Egyptian mummy DNA. Nature 1985;314:644-5.

2 Goelz SE, Hamilton SR, Vogelstein B. Purification of DNA from formaldehyde fixed and paraffin embedded human tissue. Biochem Biophys Res Commun 1985;130:118-26.

3 Dubeau L, Chandler LA, Gralow JR, Nichols PW, Jone PA. Southern blot analysis of DNA extracted from formalin-fixed pathology specimens. Cancer Res 1986; 46:2964-9.

4 Wong AJ, Ruppert JM, Eggleston J, et al. Gene amplification of c-myc and N-myc in small cell carcinoma of the lung. Science 1986;233:461-4.

5 Burmer GC, Rabinovitch PS, Loeb LA. Analysis of c-Ki-ras mutations in human colon carcinoma by cell sorting, mutations in human colon carcinoma by cell sorting, polymerase chain react

6 Fey MF, Pilkington SP, Summers C, Wainscoat JS. Molecular diagnosis of haematological disorders using DNA from stored bone marrow slides. $\mathrm{Br} J$ Haemato 1987;67:489-92.

7 Gross-Bellard M, Oudet P, Chambon P. Isolation of highmolecular-weight DNA from mammalian cells. Eur Biochem 1973;36:32-8

8 Maeda S, Uenaka H, Shiraishi N, et al. Establishment and chromosomal studies of in vitro lines of chemically induced rat erythroblastic leukemia cells. JNCI 1980;64:539-46.

9 Schwartz DC, Cantor CR. Separation of yeast chromosomesized DNAs by pulsed field gradient gel electrophoresis. sized DNAs by pulsed

10 Gardiner K, Patterson D. Transverse alternating electrophoresis. Nature 1988;331:371-2.

11 Nagasaka M, Maeda S, Sugiyama T, et al. Establishment and cytological characteristics of two in vitro $T$-cell lines derived from a child with acute lymphocytic leukemia and a man with adult T-cell leukemia in Japan. Int J Cancer 1982;30:173-80.

12 Southern EM. Detection of specific sequences among DNA fragments separated by gel electrophoresis. J Mol Biol 1975;98:503-17.

13 Seiki M, Hattori S, Hirayama Y, Yoshida M. Human adult T-cell leukemia virus: Complete nucleotide sequence of T-cell leukemia virus: Complete nucleotide sequence of the provirus genome integrated in leukemia

14 Ishikawa J, Maeda S, Takahashi R, et al. Lack of correlation between rare $\mathrm{Ha}$-ras alleles and urothelial cancer in Japan. Int J Cancer 1987;40:474-8. 